\title{
Determinants of the Quality of Life for Hemodialysis Patients
}

\author{
Danies Tunjung Pratiwi', 2), Didik Gunawan Tamtomo3), Arief Suryono4) \\ 1)School of Health Sciences Buana Husada Ponorogo, East Java \\ 2)Masters Program in Public Health, Universitas Sebelas Maret \\ 3)Faculty of Medicine, Universitas Sebelas Maret \\ 4)Faculty of Law, Universitas Sebelas Maret
}

\begin{abstract}
Background: Chronic kidney disease (CKD) is a major cause of changes in activity, psychology and life. Analysis of the use of hemodialysis on quality of life was carried out as a treatment evaluation to maintain the survival of CKD patients. This study aimed to determine the determinants quality of life among hemodialysis patients.

Subjects and Method: This was a cross-sectional study conducted at the Hospital Hemodialysis Unit Dr. Hardjono, Ponorogo, East Java, in April 2019. A total sample of 200 hemodialysis patients were selected using simple random sampling. The dependent variable was the quality of life of hemodialysis patients. The independent variables were age, gender, education, type of financing, family income, stress, frequency of hemodialysis, level of physical dependence, comorbidity, and social group. The data of life quality were collected using the Kidney Disease Quality of Life (KDQoL) SF-36 questionnaire and analyzed using multiple logistic regressions.

Results: The quality of life of hemodialysis patients was affected by age $\geq 50$ years $(b=-1.40$; CI $95 \%=-2.42$ to $-0.36 ; \mathrm{p}=0.008)$, severe stress $(\mathrm{b}=-1.73$; CI 95\% $=-2.91$ to $-0.54 ; \mathrm{p}=0.004)$, had comorbidity ( $\mathrm{b}=-1.25$; CI 95\% $=-2.29$ to -0.23 ; $\mathrm{p}=0.017)$, male sex $(\mathrm{b}=1.48$; CI 95\% $=0.41$ to $2.54 ; \mathrm{p}=0.007)$, education high $(\mathrm{b}=1.46 ; 95 \% \mathrm{CI}=0.43$ to $2.50 ; \mathrm{p}=0.006)$, family income $\geq \mathrm{mi}-$ nimum wage $(\mathrm{b}=1.98 ; 95 \% \mathrm{CI}=0.75$ to $3.20 ; \mathrm{p}=0.002)$, $\mathrm{PBI}$ financing type $(\mathrm{b}=1.69 ; 95 \% \mathrm{CI}=$ 0.40 to $2.98 ; \mathrm{p}=0.010)$, frequency of hemodialysis often $(\mathrm{b}=1.21 ; 95 \% \mathrm{CI}=0.20$ to $2.22 ; \mathrm{p}=$ o.019), independent physical dependence level $(\mathrm{b}=1.41 ; 95 \% \mathrm{CI}=0.33$ to $2.49 ; \mathrm{p}=0.011)$, and has a social group $(b=3.28 ; 95 \% \mathrm{CI}=1.12$ to $9.65 ; \mathrm{p}=0.031)$.

Conclusions: Age, gender, education, type of financing, family income, stress, frequency of hemodialysis, level of physical dependence, comorbidity, and social group affect the quality of life of hemodialysis patients.
\end{abstract}

Keywords: Chronic kidney disease, quality of life, hemodialysis, social group.

\section{Correspondence:}

Danies Tunjung Pratiwi. STIKES Buana Husada, Jl. Gabah Sinawur 9A, Ponorogo 63411, Jawa Timur. Email: daniestunjung@gmail.com. Mobile: +6285229-209108

\section{BACKGROUND}

End Stage Renal Disease (ESRD) or Chronic Kidney Disease (CKD) is a global public health problem with increased prevalence and incidence as well as poor prognosis and high costs. CKD is progressive, irreversible and leads to a series of biochemical, clinical and metabolic disorders. This disease is directly or indirectly related to the high rate of hospitalization, morbidity and mortality. Physiological and emotional problems arise during diagnosis and during treatments, patients suffer further loss in professional, social, sexual, and psychological contexts (Oliveira et al., 2016).

ESRD has a negative impact on the quality of life of patients through aspects of social, financial, and psychological health. The disease also damage the body's image and quality of life in general besides physical, functional, metabolic, social and mental conditions (Grzegorzewska et al., 2016). 
The International Society of Nephrology (ISN) and the International Federation of Kidney Foundation (IFKF) in 2013 estimated that the number of patients with CKD in 2025 in the Southeast Asia, Mediterranean and Middle East and Africa regions would continue to increase to more than 380 million people. Global Burden of Disease (GBD) states that in 2015, 1.2 million people died of kidney failure, an increase of $32 \%$ since 2005 (Wang et al., 2016).

The 9th report of the Indonesian Renal Registry (IRR) stated that $98 \%$ of patients with kidney failure underwent Hemodialysis (HD) therapy and $2 \%$ underwent Peritoneal Dialysis (PD) therapy. The number of HD patients both new patients and active patients from 2007 to 2016 has increased, especially in 2015 to 2016. Based on age, the most HD patients were the 4564 year age group, both new and active patients (IRR, 2017).

HD is a therapeutic choice for patients with renal insufficiency. HD devices are used to replace kidney function in excreting metabolic waste products and body fluids (Yusop et al., 2013). HD is carried out routinely and varies in each patient by paying attention to the number of nephrons that are still functioning, on average each patient performs 2 to 3 times a week with a duration of 4 to 5 hours each therapy (Smeltzer and Bare., 2015).

Reports from 460 HD units stating that in 2016, active patients increased sharply due to the number of patients who could undergo HD longer, suspected that the National Health Insurance (JKN) factor played a role in maintaining the continuity of this therapy. Treatment of kidney disease is the second largest ranking of funding from health BPJS after heart disease (Ministry of Health, Republic of Indonesia, 2017). The 9th IRR report shows that $90 \%$ of patient funding comes from JKN, which is a contribution assistance recipient (PBI) and not a PBI (IRR et al, 2017).

Scherer (2018) recommends that all kidney patients should get palliative care immediately after being diagnosed. This recommendation is fundamental to understanding disease progression and further treatment plans. Complications and routines of HD therapy cause various physical and psychological problems. These physical and psychological problems have an impact on the quality of life of patients with HD. This study aimed to determine the determinants of quality of life for hemodialysis patients.

\section{SUBJECTS AND METHOD \\ 1. Study Design \\ This was quantitative study with cross-sec- tional approach, conducted at Hospital He- modialysis Unit Dr. Hardjono, Ponorogo, East Java, in April 2019.}

\section{Population and Sample}

The population of this study was patients of the Hemodialysis. Total 200 patients were selected for this study by simple random sampling.

\section{Study Variables}

The dependent variable was the quality of life of hemodialysis patients. The independent variables were age, gender, education level, type of financing, family income, stress, frequency of hemodialysis, level of physical dependence, comorbidity, and social group.

\section{Operational Definition of Variables}

Quality of life was a condition that allows hemodialysis patients to carry out activities without problems due to the disease, namely; physical, psychological, social relations, and environmental health. Quality of life is measured by a questionnaire and produces continuous data.

Age was the time of life or since someone was born until now. Age is measured by 
a questionnaire and produces continuous data. Gender was the nature or condition whether they are male or female. Gender is measured by a questionnaire and produces dichotomous data.

The level of education was the level or stage of education that is set based on the level of development, goals and abilities that want to be developed. The level of education of the subjects was measured by a questionnaire and produced dichotomous data.

Family income was the amount of income received by households both from the income of the head of the household and income of household members. Family income was measured by a questionnaire and produces continuous data.

This type of financing was health financing that leads to the functioning of the health system relating to mobilization, accumulation and allocation of money to cover people's health needs, individually and collectively in the health system. The type of financing was measured by a questionnaire and produces dichotomous data.

The frequency of hemodialysis was the amount of time that many study subjects undergo hemodialysis in each month. The frequency of hemodialysis was measured by a questionnaire and produces continuous data.

Stress was the body's response to the pressure of a life situation or event. Stress was measured by a questionnaire and produces continuous data.

The level of physical dependence was a person's ability to meet the basic needs of life activities. The level of physical dependence was measured by the questionnaire and produces continuous data.
Comorbidity was the presence of one or several additional diseases or abnormalities that occur together with a primary (primary) disease or disorder that has a causal relationship. Comorbidity was measured by a questionnaire and produced dichotomous data.

Social groups were two or more people who interact with certain characteristics and have a sense of unity and mutual support. Ownership of social groups is measured by questionnaires and produces dichotomous data.

\section{Study Instruments}

Questionnaires were used to collect identity data, education level, stress status (Percieved Stress Scale), family income, frequency of hemocialysis, type of financing, level of physical dependence (Barthel Index), comorbid conditions, social group, and quality of life (KDQoL SF-36 from RAND). The process of data collection begins through interviews, direct observation and filling in instruments by the study subjects.

\section{Data Analysis}

Univariate analysis was arranged based on the frequency and percentage on each variable. Bivariate analysis was done using the chi-square test. Meanwhile, multivariate analysis was done using multiple logistic regressions.

\section{Research Ethic}

The research ethic was carried out by the Health Research Ethics Committee of Dr. Moewardi/Faculty of Medicine Hospital, Sebelas Maret University, Surakarta, Central Java, ID number: 510/IV/HREC/2019.

\footnotetext{
RESULTS

1. Samples Characteristics

The characteristics of the samples can be seen in Table 1.
} 
Indonesian Journal of Medicine (2019), 4(2): 145-154

https://doi.org/10.26911/theijmed.2019.04.02.08

Table 1. Sample characteristics

\begin{tabular}{|c|c|c|c|}
\hline \multicolumn{2}{|l|}{ Variables } & $\mathbf{n}$ & $\%$ \\
\hline \multirow[t]{2}{*}{ Quality of Life } & Poor & 148 & 74.0 \\
\hline & Good & 52 & 26.0 \\
\hline \multirow{2}{*}{ Age } & $<50$ years old & 65 & 32.5 \\
\hline & $\geq 50$ years old & 135 & 67.5 \\
\hline \multirow[t]{2}{*}{ Gender } & Female & 84 & 42.0 \\
\hline & Male & 116 & 58.0 \\
\hline \multirow[t]{2}{*}{ Educational Level } & Low & 133 & 66.5 \\
\hline & High & 67 & 33.5 \\
\hline \multirow[t]{2}{*}{ Family Income } & Low $(<$ Minimum wage) & 141 & 70.5 \\
\hline & High ( $\geq$ Minimum wage) & 59 & 29.5 \\
\hline \multirow[t]{2}{*}{ Stress } & Mild stress & 113 & 56.5 \\
\hline & Severe stress & 87 & 43.5 \\
\hline \multirow[t]{2}{*}{ Type of financing } & Non PBI & 140 & 70.0 \\
\hline & PBI & 60 & 30.0 \\
\hline \multirow{2}{*}{ Frequency of hemodialysis } & Frequent ( $\geq 7$ times per month) & 160 & 80.0 \\
\hline & Rare ( $<7$ times per month $)$ & 40 & 20.0 \\
\hline \multirow[t]{2}{*}{ Level of physical dependence } & Dependent & 65 & 32.5 \\
\hline & Independent & 135 & 67.5 \\
\hline \multirow[t]{2}{*}{ Comorbidity } & Not Having & 55 & 27.5 \\
\hline & Having & 145 & 72.5 \\
\hline \multirow[t]{2}{*}{ Social group } & Not Having & 156 & 78.0 \\
\hline & Having & 44 & 22.0 \\
\hline
\end{tabular}

\section{Bivariate Analysis}

The results of the study were analyzed by the chi square test. Table 2 showed the results of bivariate analysis of the study variables of quality of life, age, gender, education level, type of financing, family income, stress, frequency of hemodialysis, level of physical dependence, comorbidity and social group.

Table 2 Bivariate analysis of the quality of life for hemodialysis patient determinant

\begin{tabular}{lcc}
\hline \multicolumn{1}{c}{ Quality of Life } & OR & p \\
\hline Age ( $\geq 5$ O years old) & 0.32 & 0.001 \\
Gender (Male) & 3.63 & $<0.001$ \\
Educational level ( $\geq$ HS) & 6.58 & $<0.001$ \\
Family income ( $\geq$ Minimum wage) & 4.40 & $<0.001$ \\
Stress (Severe stress) & 0.25 & $<0.001$ \\
Type of financing (PBI) & 2.12 & 0.024 \\
Frequency of hemodialysis (Frequently) & 2.25 & 0.013 \\
Level of physical dependence (Independent) & 6.41 & $<0.001$ \\
Comorbidity (Having) & 0.13 & $<0.001$ \\
Social Group (Having) & 4.80 & $<0.001$ \\
\hline
\end{tabular}

\section{Multiple Logistic Regression Ana-} lysis

Multiple logistic regression analysis was applied with the STATA program 13. This multiple logistic regression model was car- ried out to eliminate the effects of confounding variables and to obtain information on the magnitude of the effect generated from the independent variables. 
Pratiwi et al./ Determinants of the Quality of Life for Hemodialysis Patients

Table 3. Multiple logistic regression analysis of the quality of life of hemodialysis patients

\begin{tabular}{|c|c|c|c|c|}
\hline \multirow{2}{*}{ Independent Variables } & \multirow{2}{*}{ b } & \multicolumn{2}{|c|}{ 95\%CI } & \multirow[b]{2}{*}{$\mathbf{p}$} \\
\hline & & Lower Limit & Upper Limit & \\
\hline Age $(\geq 50$ years old $)$ & -1.40 & -2.42 & -0.36 & 0.008 \\
\hline Gender (Male) & 1.48 & 0.41 & 2.54 & 0.007 \\
\hline Educational level ( $\geq \mathrm{HS}$ ) & 1.46 & 0.43 & 2.50 & 0.006 \\
\hline Family income ( $\geq$ Minimum wage) & 1.98 & 0.75 & 3.20 & 0.002 \\
\hline Stress (Severe stress) & -1.73 & -2.91 & -0.54 & 0.004 \\
\hline Type of financing (PBI) & 1.69 & 0.40 & 2.98 & 0.010 \\
\hline Frequency of hemodialysis (Frequently) & 1.21 & 0.20 & 2.22 & 0.019 \\
\hline Level of physical dependence (Independent) & 1.35 & 0.08 & 2.62 & 0.037 \\
\hline Comorbidity (Having) & -1.25 & -2.29 & -0.23 & 0.017 \\
\hline Social Group (Having) & 1.41 & 0.33 & 2.49 & 0.011 \\
\hline
\end{tabular}

\section{DISCUSSION}

\section{The Effect of Age on Quality of Life of Hemodialysis Patients}

The results showed a negative and significant effect of age on the quality of life of hemodialysis patients. The age of 50 years old has an average logodd score of 1.40 compared to the age of $<50$ years old.

Zyoud et al. (2016) study showed that an increase in age was indicated by a lower Health Related Quality of Life (HRQoL). This was associated with a shorter duration of disease and minor complications. According to other studies, older age was the most important predictor of lower quality of life and health status (Saffari et al., 2013). Elderly with chronic diseases were more likely to experience depression than without a history of chronic diseases (Wahyuningsih et al., 2017). Aging and development of disease lead to physical difficulties and a decrease in autonomy and independence from family and carers (Takemoto et al., 2011).

\section{The Effect of Gender on Quality of Life of Hemodialysis Patients}

The results of this study showed that there was a positive and significant effect of the gender on the quality of life of hemodialysis patients. Men have a logodd average of quality of life by 1.48 times higher than women.
This study was in line with Zyoud et al. (2016) who suggested that female gender was significantly associated with an average EQ-5D score lower than male. In addition, Ribeiro et al. (2017) also found that women have a Quality of Life (QoL) score lower than men in almost all fields, especially in domains that were associated with physical symptoms and emotional health

It seemed that this was because poor social life and lack of physical activity of women in developing countries contributed to a lower quality of life score, so women tend to have poor quality of life (Wang et al., 2016).

\section{The Effect of Educational Level on Quality of Life of Hemodialysis Patients}

The results of this study showed that there was a positive and significant effect of educational level on the quality of life of hemodialysis patients. High educational level has a logodd of quality of life by 1.46 higher compared to low education level.

A study of Javanbakht et al. (2012) showed that there was a significant relationship between high education level and high HRQoL. The fact was that educated patients were considered to have a better understanding of the disease, its effects, and have good management skills. 
In addition, high levels of education were also associated with longevity and the occurrence of disease (Cahyaningtyas et al., 2019). Subjects with higher education have a better quality of life, this was possible because of a deep understanding of the disease and adherence to therapeutic regimens (Gerasimoula et al., 2015). In addition, education can be a protective factor for a good quality of life among men (Cristina et al., 2014).

\section{The Effect of Family Income on Qu- ality of Life of Hemodialysis Pa- tients}

The results of this study showed that there was a positive and significant effect of family income on the quality of life of hemodialysis patients. Family income $\geq$ minimum wage has a logodd of quality of life by 1.98 higher compared to family income which was $<$ minimum wage.

Study done by Lemos et al. (2015) showed that from all samples with income greater than the minimum wage, they have a better quality of life in terms of physical function, pain and social aspects, physical, emotional and mental health roles. The economic condition of low income families suffering from CKD was increasingly at risk of decreasing economic welfare and quality of life.

Income was one of the ways to fulfill someone's substantial needs. Individual welfare depend on demographic, social, and psychological factors along with good income to take care of oneself and family (Wang et al., 2016).

\section{The Effect of Stress on Quality of Life of Hemodialysis Patients}

The results showed that there was a negative and significant effect between stress on quality of life. Severe stress has a logodd value of quality of life by 1.73 higher compared to mild stress.

This study was in line with Ribeiro et al. (2017) who examined the negative relationship between stress and quality of life in students, through decreasing various aspects related to physical and mental health. High stress and poor quality of life Quality of Life (QoL) can inhibit the patient's prognosis (Wang et al., 2016).

\section{The Effect of Type of Financing on Quality of Life of Hemodialysis Pa- tients}

The results of the study showed that there was a positive and significant influence between the types of financing on quality of life. PBI financing types have a logd of quality of life by 1.69 higher compared to non PBI.

This study was in line with Penson et al. (2001) who stated that health insurance status seemed to have a unique effect on the results of Health Related Quality of Life (HRQoL) common in men after treatment for prostate cancer. This study confirmed that not having insurance tend to have a worse quality of life. Involvement with all relevant stakeholders and innovative financing strategies that was needed to maximize equitable access to treatment (Luyckx et al, 2018).

\section{The Effect of Frequency of Hemo- dialysis on Quality of Life of Hemo- dialysis Patients}

The results of this study indicated a positive and significant influence of the frequency of hemodialysis on quality of life. The frequency of hemodialysis often has a logod of quality of life by 1.21 of rare frequency.

This study was in line with Shafiee et al. (2017) who stated that patients who can have greater nutrition through higher HD frequencies would have a better quality of life, especially due to the influence of malnutrition on morbidity and mortality.

The physiological improvement shown by Extended Hemodialysis (EHD) patients played a major role in determining the 
quality of life of CKD and ESRD patients. There were several factors that can be demonstrated and would have an impact on the quality of life of patients in an objective manner, and be increased through increasing the frequency of HD.

Weight gain was one of the most important factors of the patient's inter-dialytic residue. Higher inter-dialytic weight gain has been shown to significantly increase diastolic blood pressure in patients (Ipema et al., 2016).

\section{The Effect of Level of Physical De- pendence on Quality of Life of He- modialysis Patients}

The results of this study showed that there was a positive and significant influence of the level of physical dependence on the quality of life of hemodialysis patients. The level of independent physical dependence has logodd quality of life by 1.41 higher compared to dependent patients.

This study was in line with Barbosa et al. (2017) who stated that physical limitations were the most influential dimensions of quality of life. Physical limitations resulting from CKD and by the duration of $\mathrm{HD}$ treatment may be a consequence of systemic changes caused by diseases, especially those which were related to musculoskeletal disorders, in addition to factors such as dependence on medical support, having a strict treatment regimen, pain and suffering during sessions, sleep disturbances, immobility, machine dependence, specific diets and changes in body image.

Physical factors influenced psychological factors as much as psychological factors influenced physical factors (Grasselli et al., 2012). Physical complications brought concern about the loss of autonomy and increased dependence on others to carry out daily living activities. In addition, these factors can also affect the emotional health and quality of life of patients with kidney disease

\section{The Effect of Comorbidity on Qua- lity of Life of Hemodialysis Pa- tients}

The results of this study indicated that there was a negative and significant influence of comorbidity on the quality of life of hemodialysis patients. Having comorbidity has a logodd value of quality of life by 1.25 higher compared to not having comorbidities.

This result was in line with a study done by Barbosa et al. (2017) which showed that the presence of comorbidity was an important predictor of mortality. The study showed a decrease in quality of life for CKD patients associated with cardiovascular disease.

Another study by Nelis et al. (2018) provided additional evidence that comorbidity has a large impact on someone's subjective perceptions of poor health and the welfare perception associated with dementia.

\section{The Effect of Social Group on Quality of Life of Hemodialysis Patients}

The results showed that there was a positive and significant influence of social groups on the quality of life of hemodialysis patients. Ownership of social groups has a logodd of quality of life by 3.28 times higher compared to not having a social group.

Study by Fajriyah et al. (2017) showed the influence of support groups on the quality of life of patients with chronic diseases. The result of this study was in line with Oliveira et al. (2016) who stated that health status has an impact on the quality of socialization and vice versa. Family involvement would support sick relatives and made them responsible for care. This was the best way to prevent patient absence. At the same time, families must support pati- 
ent autonomy to prevent them from experiencing psychological problems.

Psychology played an important role in achieving higher QoL scores because it encouraged patients to adapt and deal with their problems, as well as abilities related to balancing their lives in social settings and treatment (Oliveira et al., 2016).

\section{AUTHOR CONTRIBUTION}

Danies Tunjung Pratiwi, the main author, played a role in collecting, processing and compiling reports. Didik Tamtomo gave input on study methods. Arief Suryono provided input regarding the type of financing.

\section{FUNDING AND SPONSORSHIP}

The source of study funding was independent costs by the authors.

\section{CONFLICT OF INTEREST}

None.

\section{ACKNOWLEDGEMENT}

We would like to thank the Head of Hemodialysis Unit and patients who have been willing to participate as the study subjects.

\footnotetext{
REFERENCE

Barbosa JBN, Moura ECSC, Lira CLOB, Marinho PEM (2017). Quality of life and duration of hemodialysis in patients with chronic kidney disease (CKD): a cross-sectional study. Fisioter Mov Curitiba, 30(4): 781-788. doi 10.1590/1980-5918030.004.AO13

Cahyaningtyas NA, Sudiyanto A, Soemanto RB (2019). Socioeconomic determinants of healthy ageing and the contextual effect of peer group: A multilevel evidence from Blora Central Java. Journal of Epidemiology and Public Health 4(1): 30-36. doi: 10.26911/ jepublichealth.2019.04.01.04
}

Fajriyah YL, Demartoto A, Murti B (2017). The effect of depression, stigma, and peer support group, on the quality of life of people living with HIV/ AIDS in solo plus peer support group Surakarta, Central Java. Journal of Health Promotion and Behavior, 3(1): 27-36. doi: doi.org/10.26911/thejhpb.2018.03.01.03

Gerasimoula K, lefkothea L, Maria L, Victoria A, Paraskevi T, Maria P (2015). Quality of life in hemodialysis patients. Meter Sociomed, 27 (5): 305309. doi: 10.5455/msm.2015. 27.305309.

Grasselli CSM, Chaves ECL, Simao TP, Botelho PB, Silva RR (2012). Avaliação da qualidade de vida dos pacientes submetidos à hemodiálise. Rev Brasileira de Clinica Medica 10(6): 503-507.

Grzegorzewska AE, Izdebska A, Niepolski L, Warchol W, Jagodzinski PP (2016). Self-reported physical activity, quality of life, and psychological status in relation to plasma 25-hydroxyvitamin $\mathrm{d}$ concentration in patients treated with hemodialysis. Kidney and Blood Pressure Research, KARGER 41(6): 886-90o. doi:10.1159/000452585.

Ipema KJR, JKuipers J, Westerhuis R, Baillard CAJM, Schans CP, Krijinen W, Franssen CFM (2016). Causes and consequences of interdialytic weight gain. Kidney and Blood Research, KARGER 41: 710-720. doi: 10.1159/ O00450560.

IRR (2017). 9 th Report Of Indonesian Renal Registry 2016, 1-46. https://www.indonesianrenalregistry.org/

Javanbakht M, Abolhasani F, Mashayekhi A, Baradaran HR, Jahangiri Y (2012). Health Related quality of life in patients with type 2 diabetes mellitus in Iran: A national survey. PLoS ONE 
7(8): 1-9. doi: 10.1371/ journal.pone.0044526 .

Lemos CF, Podrigeus MP, Veiga JRP (2015). Family income is associated with quality of life in patients with chronic kidney disease in the predialysis phase: a cross sectional study. Health and Quality of Life Outcomes, BioMed Central, 13 (202): 1-9. doi: 10.1186/s12955-015-0390-6.

Luyckx VA, Tonelli M, Stanifer J (2018). The global burden of kidney disease and the sustainable development goals. Bull World Health Organ, 96: 414-422. doi:10.2471/BLT.17.206441

Ministry of Health RI (2017). Infodatin situasi penyakit ginjal kronis, Pusat Data dan Informasi Kementerian Kesehatan RI.

Murti, B (2018). Prinsip dan Metode Riset Epidemiologi. 4th edn. Fajar Offset.

Nelis SM, Wu YT, Matthews FE, Martyr A, Quinn C, Rippon I, Rusted J (2018). The impact of comorbidity on the quality of life of people with dementia: findings from the IDEAL study. Age and Ageing. Oxford University Press on behalf of the British Geriatrics Society, 0: 1-7. doi: 10.1093/ageing/afy155.

Oliveira APB, Schmidt DB, Amatneeks TM, Santos JC, Cavallet LHR, Michel RB (2016). Quality of life in hemodialysis patients and the relationship with mortality, hospitalizations and poor treatment adherence. Jornal Brasileiro de Nefrologia, 38(4): 411-420. doi: 10.5935/0101-2800.20160066.

Penson DF, Stoddard ML, Pasta DJ, Lubeck DP, Flanders SC, Litwin MS (2001). The association between socioeconomic status, health insurance coverage, and quality of life in men with prostate cancer. Journal of Clinical Epidemiology 54 (2001): 350-358. https:-
//doi.org/10.1016/So895-4356(oo)o0312-7.

Ribeiro ÍJS, Pereira R, Freire IV, Oliviera BG, Casotti CA, Boery EN (2018). Stress and quality of life among university students: A systematic literature review. Health Professions Education. Elsevier B.V. 4(2): 70-77. doi: 10.1016/ j.hpe.2017.03.002.

Saffari M, Pakpour AH, Naderi MK, Koeing HG, Baldacchino DR, Piper CN (2013). Spiritual coping, religiosity and quality of life: A study on muslim patients undergoing haemodialysis. Nephrology, Asian Pacific Society of Nephrology, 18(4): 269-275. doi: 10.1111/nep.12041.

Scherer J (2018). National Kidney Foundation. Available at: https://www.kidney.org/atoz/content/how-does-palliative-care-improve-quality-life-kidney-patients. diakses 23 januari 2019.

Shafiee MA, Chamanian P, Shaker P, Shahideh Y, Broumand B (2017). The impact of hemodialysis frequency and duration on blood pressure management and quality of life in end-stage renal disease patients. Healthcare 5(52): 1-9. doi: 10.3390/ healthcare5030052.

Smeltzer SC, Bare BG (2015). Keperawatan Medikal Bedah. 8th. Jakarta: EGC.

Takemoto AY, POkubo P, Bedebdo J, Carreira L (2011). Avaliação da qualidade de vida em idosos submetidos ao tratamento hemodialítico. Revista Gaúcha de Enfermagem, 32(2): 256262. doi: 10.1590/s1983-14472011000200007.

Wahyuningsih CS, Subijanto AA, Murti B, (2017). Logistic regression on factors affecting depression among the elderly. Journal of Epidemiology and Public Health 4(3): 171-179. doi: 10.26911/jepublichealth.2019.04.0303 
Indonesian Journal of Medicine (2019), 4(2): 145-154

https://doi.org/10.26911/theijmed.2019.04.02.08

Wang H, Naghavi M, Allen C, Barber RM, Bhutta ZA, Carter A, Casey DC (2016). Global, regional, and national life expectancy, all-cause mortality, and cause-specific mortality for 249 causes of death. 1980-2015: a systematic analysis for the Global Burden of Disease Study 2015. The Lancet, 388(10053): 1459-1544. doi: 10.1016/So140-6736(16)31012-1.

Yusop NBM, Mun CY, Shariff ZM, Huat CB (2013). Factors associated with qua- lity of life among hemodialysis patients in malaysia. PLoS ONE 8(12): 1-11. doi: 10.1371/journal.pone.0084152.

Zyoud SH, Daraghmeh DN, Mezyed DO, Khdeir RL, Sawfta MN, Ayaseh NA, Tabeeb GH, et al. (2016). Factors affecting quality of life in patients on haemodialysis: a cross-sectional study from Palestine. BMC Nephrology., 17(44): 1-12. doi: 10.1186/s12882-016-0257-z. 